\title{
Crack Initiation Behaviors of Granite Specimens Containing Crossing-Double-Flaws with Different Lengths under Uniaxial Loading
}

\author{
Haiyang Pan $\left(\mathbb{D},{ }^{1,2}\right.$ Dawei Yin $\mathbb{D}^{1,},{ }^{1,3}$ Ning Jiang $\mathbb{D}^{1},{ }^{1}$ and Zhiguo Xia $\mathbb{D}^{1}$ \\ ${ }^{1}$ State Key Laboratory of Mine Disaster Prevention and Control, Shandong University of Science and Technology, \\ Qingdao 266590, China \\ ${ }^{2}$ General Institute of Exploration and Research of China National Administration of Coal Geology, Beijing 10039, China \\ ${ }^{3}$ Key Laboratory of Safety and High-Efficiency Coal Mining, Ministry of Education, Anhui University of Science and Technology, \\ Huainan 232001, China \\ Correspondence should be addressed to Dawei Yin; 949251142@qq.com
}

Received 24 May 2020; Revised 19 July 2020; Accepted 29 July 2020; Published 24 August 2020

Academic Editor: Hailing Kong

Copyright (C) 2020 Haiyang Pan et al. This is an open access article distributed under the Creative Commons Attribution License, which permits unrestricted use, distribution, and reproduction in any medium, provided the original work is properly cited.

Crack initiation is an important stage in the failure process of rock masses. In this paper, crack initiation behaviors (crack initiation model, crack initiation location, crack initiation angle, and crack initiation stress) of granite specimens containing crossing-double-flaws with different lengths were investigated using $\mathrm{PFC} 2^{\mathrm{D}}$ software. Crack initiation models were all tensile wing cracks, which did not exactly initiate from the main flaw with a length of $30 \mathrm{~mm}$. They can initiate from the secondary flaw with a length $20 \mathrm{~mm}$ at $\alpha$ of $30^{\circ}$ (included angle between main flaw and horizontal direction) and $\beta$ of $90^{\circ}$ (included angle between main and secondary flaws) and from main and secondary flaws at $\alpha$ of $30^{\circ}$ and $\beta$ of $60^{\circ}$. These were mainly induced by the superposition of stress fields around the main and secondary flaws as $\beta$ varied from $0^{\circ}$ to $90^{\circ}$, especially the tensile force concentration zones superposition. The tensile forces concentration zone around flaw shrank towards flaw tips with the increase of flaw's inclinations measured horizontally. Under stress field superposition effects, the crack initiation stress decreased firstly and then increased with $\beta$ at $\alpha$ of $30^{\circ}$ and $45^{\circ}$. Crack initiation locations were close to flaw tips but not restricted to them. The distances between crack initiation locations and flaw tips, and the crack initiation angles depended on the flaw where first macrocracks initiated from. Microdisplacement field distributions of granite specimens to reveal the mesomechanism of crack initiation behaviors were discussed.

\section{Introduction}

Under different geological processes, the rock masses contain various discontinuities such as joints, fissures, cracks, and faults [1-8]. The failure process of rock masses is characterized by several distinct deformation stages, including the crack initiation, propagation, and coalescence. The crack initiation illustrates how and where new cracks start in the rock masses [9], and the corresponding crack initiation stress is the stress level marking the initiation of the microfracturing process [10]. Therefore, it is very important to investigate the crack initiation behaviors of the flawed rock masses in rock engineering.
For decades, the investigations on crack initiation behaviors have been conducted on the rock or rock-like specimens with artificial flaws by the laboratory tests and numerical simulations. Most of these studies have been performed on different materials containing single flaw [11-14], two or more parallel flaws [15-19], two or more nonparallel flaws [20-23], three flaws [24-26], and threedimensional (3D) flaws [27-29]. Moreover, the crack initiation behaviors of rock-coal composite specimens with original coal flaw were studied by Chen et al. [30,31] and Yin et al. [32]. In addition, to analyze the crack initiation behavior, many crack initiation criteria were proposed, which mainly include the stress-based, energy-based, and strain- 
based according to the parameter evaluated around the preexisting flaw tips [33]. Through the development and propagation of secondary shear cracks under uniaxial compression tests, the damage model based on the maximum tensile principal [34] and F-criterion [35] were proposed.

In nature, the rock mass may contain one or more sets of crossing-double-flaws [31, 36-38]. The strength and failure characteristics of rock specimens containing a set of crossing-flaws [31, 38] and two sets of crossing-flaws [36, 37] were studied, respectively. There are few studies on the crack initiation behavior of rock specimen containing crossingflaws. In this investigation, the uniaxial compression tests on the granite specimens containing crossing-double-flaws with different lengths were simulated by Particle Flow Code (PFC). Their crack initiation behaviors were the main target of this investigation, including the crack initiation model, crack initiation location, crack initiation angle, and crack initiation stress.

\section{Numerical Model and Microparameters}

In the PFC software, two main bonded-particle models are provided, i.e., contact model and parallel bond model. Generally, both forces and bending moments between particles can be transmitted in the parallel bond model $[31,32]$, which is well selected to simulate the mechanical behaviors of the compact materials, such as rock or coal. Therefore, numerical models for granite specimens containing crossing-double-flaws of different lengths were built using the parallel bond model in this study.

2.1. Model Description. Numerical models for granite specimens containing crossing-double-flaws of different lengths were shown in Figure 1. The model size is $70 \mathrm{~mm} \times 140 \mathrm{~mm}$. The uniform distribution of particles can better model the mechanical behaviors of rock. Therefore, the particle radius followed a uniform distribution ranging from 0.3 to $0.498 \mathrm{~mm}$. Each intact numerical model contained 16459 particle samples. The crossing-double-flaws were created by deleting particles in the intact numerical model center. The flaw with a large length of $30 \mathrm{~mm}$ is described as the main flaw, and the flaw with a small length of $20 \mathrm{~mm}$ is the secondary flaw. The widths of main and secondary flaws are all $1 \mathrm{~mm}$. The included angle between the main flaw and horizontal direction is $\alpha$, which are $30^{\circ}$ and $45^{\circ}$, respectively. $\beta$ is taken as the included angle between main and secondary flaws, which are $0^{\circ}, 30^{\circ}, 45^{\circ}, 60^{\circ}$, and $90^{\circ}$, respectively.

The granite specimens were loaded vertically in a constant displacement-control manner, which was performed by moving upper and lower walls. In order to ensure the granite specimens remain a quasi-static equilibrium throughout the test, upper and lower walls moved at a rate of $0.05 \mathrm{~m} / \mathrm{s}$. Loading was continuously terminated until failure occurred, which was defined as a drop of postpeak axial stress down to $80 \%$ of the peak stress.
2.2. Microparameters of Granite Specimens. Appropriate microparameters should be selected before modeling through a calibration process. Due to the limitation of laboratory test conditions, the microparameters (Table 1) of granite specimen provided by Yin et al. [38] and Zhang et al. [39] were used to carry out the numerical tests, which were described in detail as follows. Young's modulus of the particle and parallel bond modulus are $3 \mathrm{GPa}$ and $43 \mathrm{GPa}$, respectively. The ratios of normal to shear stiffness of the particle and parallel bond are all 3. The particle friction coefficient is 0.8 . The parallel bond radius multiplier is 1 . The tensile and shear strengths of the parallel bond are $88 \mathrm{MPa}$ and $160 \mathrm{MPa}$, respectively.

Figure 2 illustrates the comparison of stress-strain curves and failure models obtained by the laboratory test and numerical simulation, respectively.

The simulated stress-strain curve and failure pattern were in excellent agreement with the laboratory test. The values of elastic modulus, peak stress, Poisson ratio, cohesive force, and internal friction angle of the numerical model were $28.4 \mathrm{GPa}, 132.8 \mathrm{MPa}, 0.2285,20.87 \mathrm{MPa}$, and $43.68^{\circ}$, respectively. The corresponding experimental results were 28.7 GPa, $130.5 \mathrm{MPa}, 0.2300,15.9 \mathrm{MPa}$, and $49.86^{\circ}$, respectively. The elastic modulus, peak stress, and Poisson ratio of the numerical results were basically equal to the experimental results. Therefore, the macromechanical properties of the numerical model were basically coincident with the granite specimen in the laboratory test. Due to circular particles used in the numerical model, relatively large differences were found in the cohesive forces and internal friction angles obtained by the laboratory test and numerical simulation [38, 39].

2.3. Determination of Crack Initiation Behavior. During the loading process, when the axial stress $\sigma$ reaches to the crack initiation stress of granite specimen, first macrocracks initiate from the pre-existing flaw. In the parallel bond model, under $\sigma$, the parallel bond between adjacent parent particles can be broken when the stress intensity transmitted between the particles exceeds the parallel bonding strength between particles. Thus, a microcrack is generated. Each microcrack is represented as a straight line of length equal to the average value of the diameters of two parent particles. Because the individual bonds are discrete, the microcracks formed in neighbouring particles are also discrete and not connected, which are in contrast to those observed in physical tests and numerical studies based on the finite element method. To better visualize the crack initiation behavior, close enough discrete microcracks are artificially linked up to form a continuous macrocrack path. According to the previous studies, the distance of the centroids of two adjacent microcracks was defined as $l$, and the microcrack length was long as $L$. If $(l / L) \leq 1$, two microcracks would be treated to be a single continuous macrocrack and a macrocrack trace line can be then be drawn to link the centroids of two microcracks, as shown in Figure 3 [33]. A macrocrack is described to have formed when three or more microcracks are connected through this method in this study. 


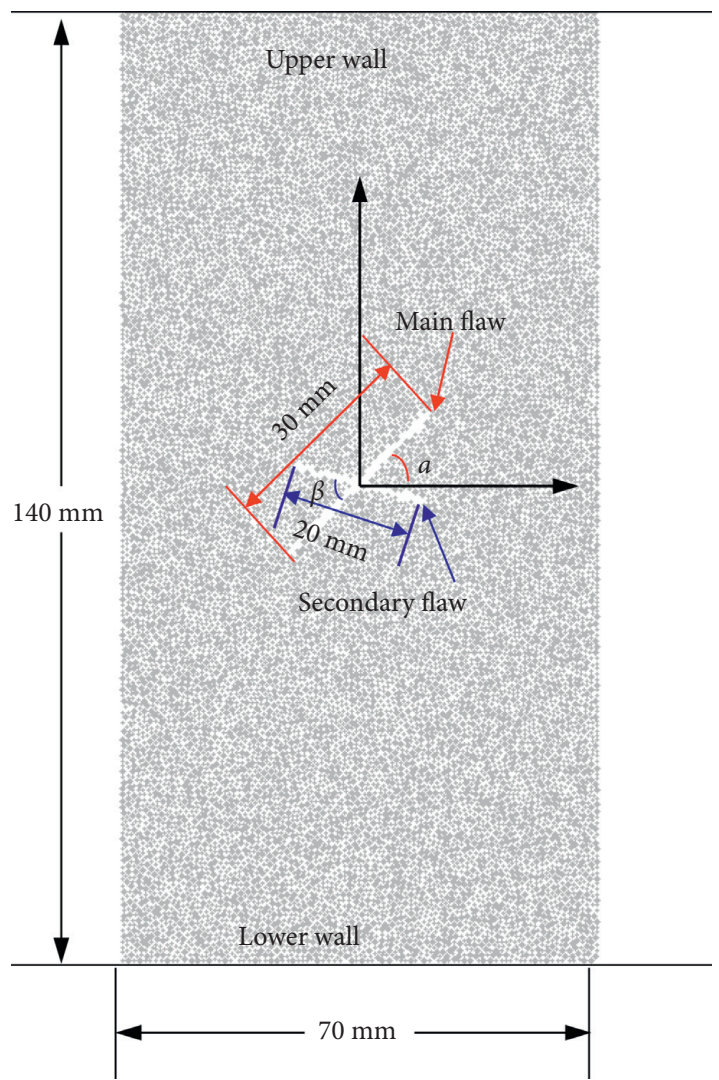

Figure 1: Numerical model for granite specimens containing crossing-double-flaws of different lengths.

TABLE 1: Microparameters of granite specimen [38, 39].

\begin{tabular}{lc}
\hline Microparameters & Values \\
\hline Minimum particle radius $(\mathrm{mm})$ & 0.3 \\
Ratio of maximum to minimum of radius & 1.66 \\
Particle density $\left(\mathrm{kg} / \mathrm{m}^{3}\right)$ & 2800 \\
Particle friction coefficient & 0.8 \\
Young's modulus of the particle $(\mathrm{GPa})$ & 5 \\
Ratio of normal to shear stiffness of the particle & 3 \\
Young's modulus of the parallel bond $(\mathrm{GPa})$ & 43 \\
Ratio of normal to shear stiffness of the parallel bond & 3 \\
Tensile strength of the parallel bond & 88 \\
Shear strength of the parallel bond & 160 \\
Parallel bond radius multiplier & 1 \\
\hline
\end{tabular}

Figure 4 shows the crack initiation, propagation, and coalescence processes of the numerical model for granite specimen $\left(\alpha=45^{\circ}\right.$ and $\left.\beta=0^{\circ}\right)$. In Figure 4 , microcracks are presented in black colour. When $\sigma$ reached up to $35.604 \mathrm{MPa}$ (crack initiation stress), the granite specimen occurred crack initiation, and macrotensile cracks (first macrocrack) initiated from flaw tips. As $\sigma$ increased further to $76.217 \mathrm{MPa}$, the secondary shear cracks initiated in the flaw areas. With the propagation and coalescence of the first and secondary cracks, the specimen failed. The peak stress of granite specimen was $86.684 \mathrm{MPa}$. The ratio of crack initiation stress to peak stress was about 0.411 . The crack initiation behavior of the numerical model basically agreed with previous investigations [9-16,33], verifying the accuracy of numerical simulations. Numerical simulations for other granite specimens with crossing-double-flaws of different lengths were conducted to investigate their crack initiation behaviors.

\section{Crack Initiation Behaviors of Granite Specimens}

The crack initiation locations of first macrocracks on the flaw periphery relative to the flaw tips were $d_{1}$ and $d_{2}$, respectively, and crack initiation angles were presented as $\theta_{1}$ and $\theta_{2}$, respectively, as shown in Figure 5. Table 2 shows the typical first macrocracks, crack initiation stresses, crack initiation angles, and crack initiation locations of granite specimens under different simulation conditions, which were analyzed as follows.

3.1. Crack Initiation Model. First macrocracks of granite specimens under different simulation conditions were all tensile in origin, which were consistent with previous fields and experimental investigations $[17,40]$. When $\alpha$ was $45^{\circ}$ and $\beta$ varied from $0^{\circ}$ to $90^{\circ}$, first macrocracks initiated from the main flaw. When $\alpha$ was $30^{\circ}$ and $\beta$ was between $0^{\circ}$ and $45^{\circ}$, first macrocracks originated from the main flaw. However, when $\alpha$ was $30^{\circ}$ and $\beta$ was $60^{\circ}$, first macrocracks originated from main and secondary flaws (upper tip region of main flaw and lower tip region of secondary flaw). First, macrocracks initiated from the secondary flaw at $\alpha$ of $30^{\circ}$ and $\beta$ of $90^{\circ}$. Meanwhile, these first macrocracks later propagated towards the vertical loading direction. This phenomenon was caused the superposition effects of stress fields around main and secondary flaws, which were discussed in the section of stress and displacement fields analysis.

3.2. Crack Initiation Location and Crack Initiation Angle. The initiation locations of first macrocracks were close to flaw tips but not restricted to them, which were similar to research results studied by Wong [40] through physical and numerical tests. Figure 6 gives the variations of crack initiation locations with $\beta$. The variations of crack initiation angles with $\beta$ were presented in Figure 7 . The $d$ was the mean value of $d_{1}$ and $d_{2}$, and the $\theta$ was the mean value of $\theta_{1}$ and $\theta_{2}$.

The values of $d$ and $\theta$ were related to the included angle of $\varphi$ between the flaw (where first macrocracks initiated from) direction and horizontal direction. Generally, the crack initiation location in a single flawed specimen shifted from flaw tips towards the flaw center as $\varphi$ decreased, and the crack initiation angle increased with the increase of $\varphi$ $[13,14,33]$. These mean the larger $\varphi$ was, the smaller $d$ was and the greater $\theta$ was. First, macrocracks initiated from main flaw at $\alpha$ of $45^{\circ}$ and $\beta$ varied from $0^{\circ}$ to $90^{\circ}$, and the $d$ and $\theta$ did not obviously change with $\beta$. When $\alpha$ was $30^{\circ}$ and $\beta$ varied from $0^{\circ}$ to $45^{\circ}$, first macrocracks initiated from the main flaw. First, macrocracks originated from main and secondary flaws at $\alpha$ of $30^{\circ}$ and $\beta$ of $60^{\circ}$, and $\varphi$ was $-30^{\circ}$ along the clockwise direction. Therefore, $d$ and $\theta$ did not also change with $\beta$ varying from $0^{\circ}$ to $60^{\circ}$. However, the first macrocracks originated from secondary flaw at $\alpha$ of $30^{\circ}$ and $\beta$ of $90^{\circ} . \varphi$ was $-60^{\circ}$ along the clockwise direction. Thus, the $d$ 


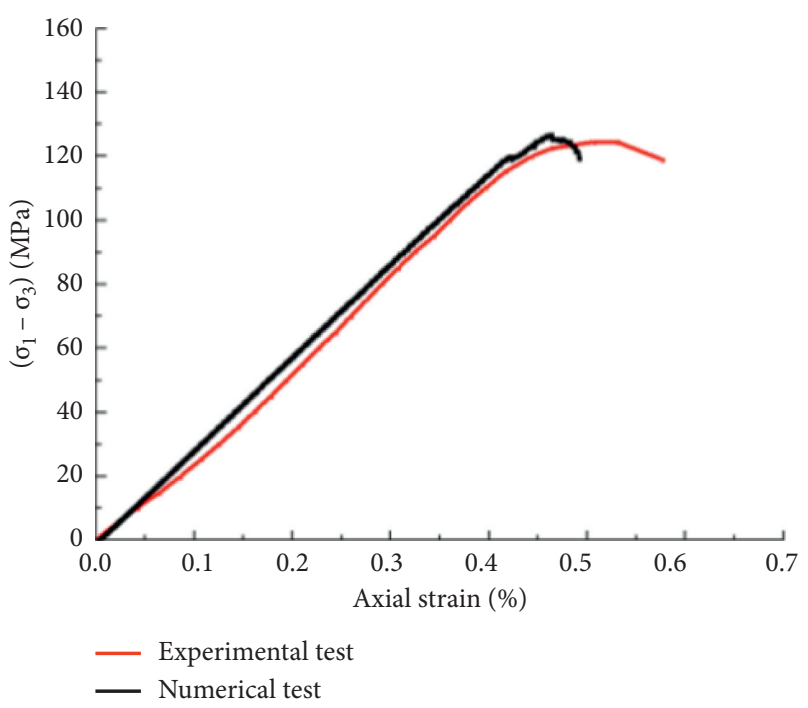

(a)
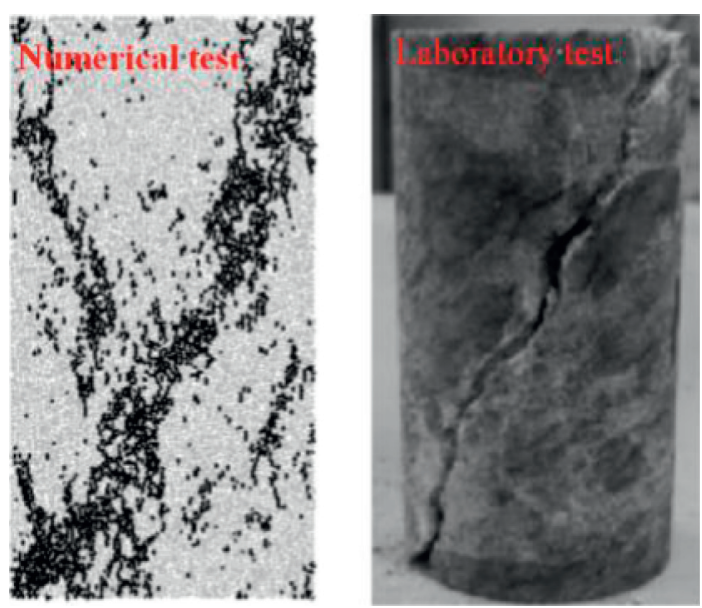

(b)

Figure 2: Comparisons of stress-strain curves and failure patterns between experimental and numerical results [38, 39]. (a) Stress-strain curve comparison. (b) Failure pattern comparison.

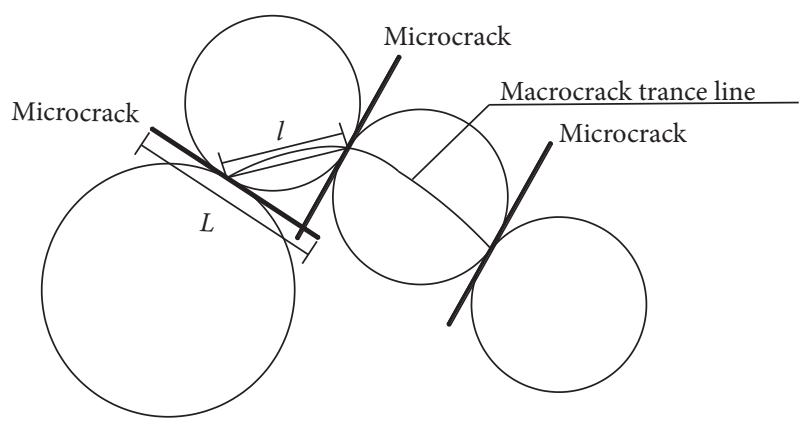

FIGURE 3: Constructing a macrocrack based on connecting centroids of microcracks [33].

showed a steep decrease and $\theta$ presented a steep increase $\alpha$ of $30^{\circ}$ and $\beta$ of $90^{\circ}$. In addition, the $d$ at $\alpha$ of $30^{\circ}$ was larger than that at $\alpha$ of $45^{\circ}$, and the $\theta$ at $\alpha$ of $30^{\circ}$ was lower than that at $\alpha$ of $45^{\circ}$ (except $\alpha$ of $30^{\circ}$ and $\beta$ of $90^{\circ}$ ).

3.3. Crack Initiation Stress. Crack initiation stresses of granite specimens under different simulation conditions are denoted in Figure 8. It can be obviously seen that the crack initiation stress decreased firstly and then increased gradually with an increase of $\beta$. When $\alpha$ was $30^{\circ}$, the crack initiation stress was the smallest at $\beta$ of $30^{\circ}$. While, the crack initiation stress at $\beta$ of $45^{\circ}$ was the lowest at $\alpha$ of $45^{\circ}$. It was well known that the stress filed in the rock specimen changed due to the flaw existence. The stress concentrations were generated near the flaw. When the stress intensity factor near the flaw exceeded the fracture toughness of specimen, the flaw can fracture and first macrocracks initiated from the flaw. First, macrocracks typically initiated from the tensile stress concentration regions near the flaw. In this study, the stress filed around the secondary flaw varied with $\beta$. If the tensile force concentration regions around main and secondary flaws were overlapped, the crack initiation behavior was strengthened and the corresponding crack initiation stress was relatively low. If the tensile force concentration region was overlapped with the compression force concentration region, the crack initiation behavior was weakened and the corresponding crack initiation stress was relatively high. And variations of crack initiation stresses with $\beta$ were mainly induced by the superposition effects of stress fields around main and secondary flaws, which were analyzed as follows.

\section{Stress and Displacement Field Analysis}

4.1. Stress-Filed Analysis. In the parallel bond model, when the stress intensity transmitted between the particles exceeded the parallel bonding force between the particles, a microcrack was generated. In order to analyze the superposition effects of stress fields around main and secondary flaws, Table 3 gives the parallel bonding forces around the single flaw with different included angles of $\varphi$ between the flaw direction and horizontal direction when first macrocracks initiated. The red segment stands for the tensile force, and the compression force is presented in the black segment. Among them, the thick blue line with an arrowhead stands for the shrink direction of tensile force concentration zone.

In Table 3, the red segments were almost around the flaw at $\varphi$ of $0^{\circ}$ except at the flaw tips. The flaw tips were only surrounded by black segments. These illustrate that the flaw perimeter was in a state of tension, and the flaw tips' areas were in a state of compression. With an increase of $\varphi$, the black segments' (compression force) regions expanded gradually from the left flaw tip towards the right flaw tip above the flaw surface and from the right tip towards the left tip beneath the flaw surface. Correspondingly, the red segments regions around the flaw perimeter gradually shrank towards the flaw tips with the increase of $\varphi$. Namely, the tensile force concentration region shrank towards flaw tips with the increase of $\varphi$. These results agreed well with that 


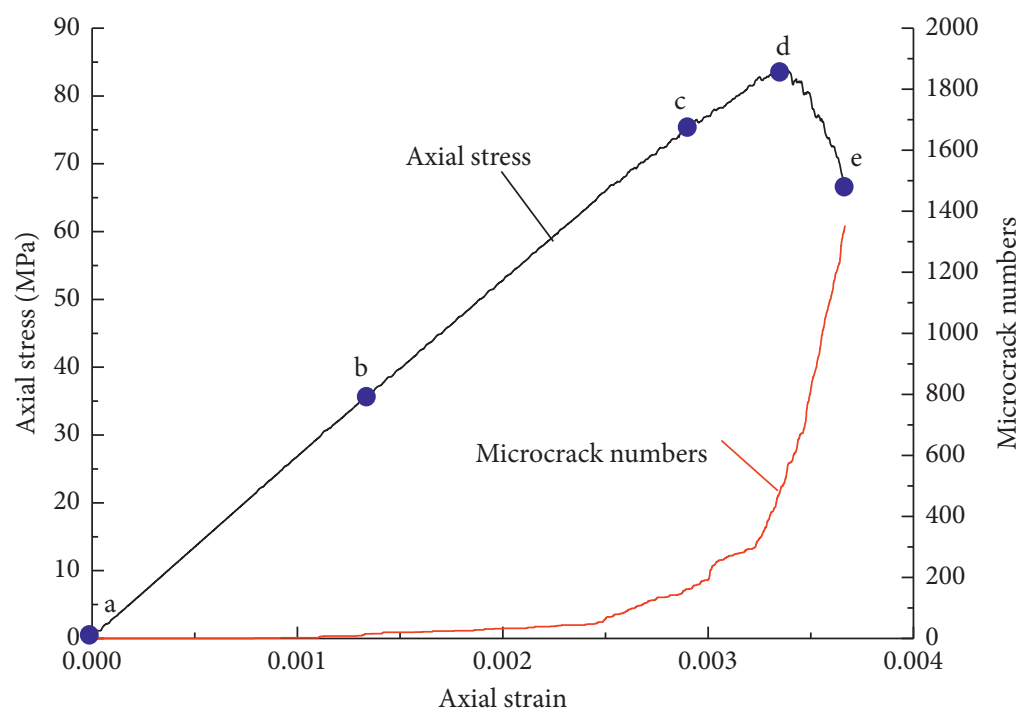

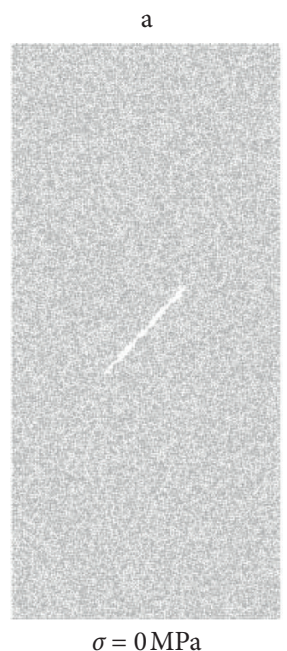

$\sigma=0 \mathrm{MPa}$

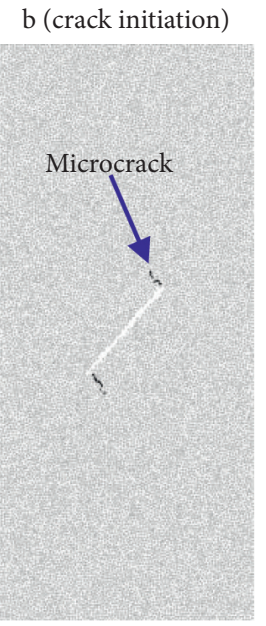

$\sigma=35.604 \mathrm{MPa}$ c

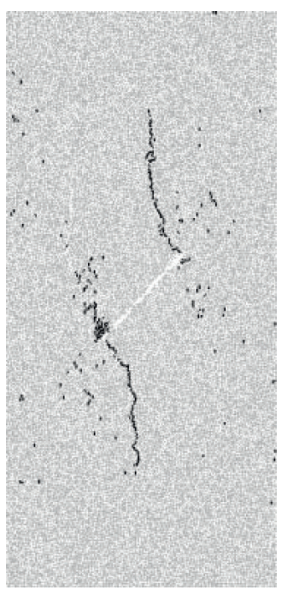

$\sigma=76.217 \mathrm{MPa}$

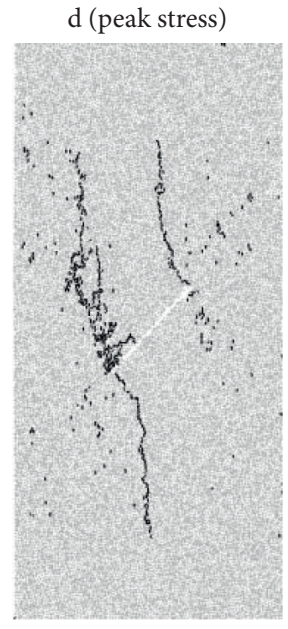

$\sigma=86.684 \mathrm{MPa}$

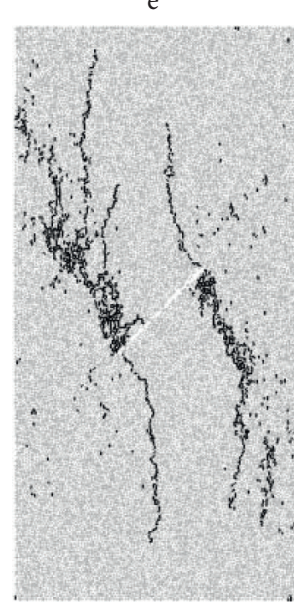

After failure

FIGURE 4: Crack initiation, propagation, and coalescence processes of the numerical model for granite specimen $\left(\alpha=45^{\circ}\right.$ and $\left.\beta=0^{\circ}\right)$.

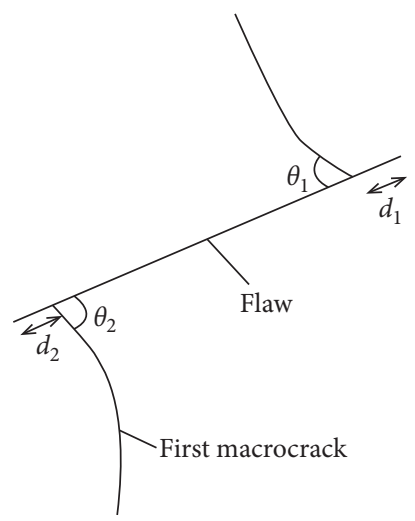

FIgURE 5: Crack initiation angles and distances between first macrocrack initiation locations and flaw tips [36].

studied by Zhang and Wong [33] and Lajtai [41]. The first macrocracks typically initiated from the tensile stress concentration regions. Therefore, in this study, due to the shrink of the tensile forces' concentration region towards flaw tips, the average distance between the crack initiation locations and flaw tips decreased with the increase of $\alpha$ and the average distance showed a steep decrease at $\alpha$ of $30^{\circ}$ and $\beta$ of $90^{\circ}$, as shown in Figure 6.

For the granite specimens containing crossing-doubleflaws of different lengths, if the tensile force distribution regions around main and secondary flaws were superimposed, the crack initiation behavior was enhanced and first macrocracks may easily be initiated from main flaw or secondary flaw or both main and secondary flaws. The corresponding crack initiation stress was relatively large. If not, the crack initiation behavior was weakened and the corresponding crack initiation stress was relatively small. The superposition effects of stress fields around main and secondary flaws at $\alpha$ of $30^{\circ}$ and $45^{\circ}$ were analyzed as follows.

4.1.1. $\alpha=30^{\circ}$. Table 4 gives the parallel bonding forces around the crossing-double-flaws at $\alpha$ of $30^{\circ}$ when first macrocracks initiate. In Table 4, the red segment stands for the tensile force and the compression force is presented in 


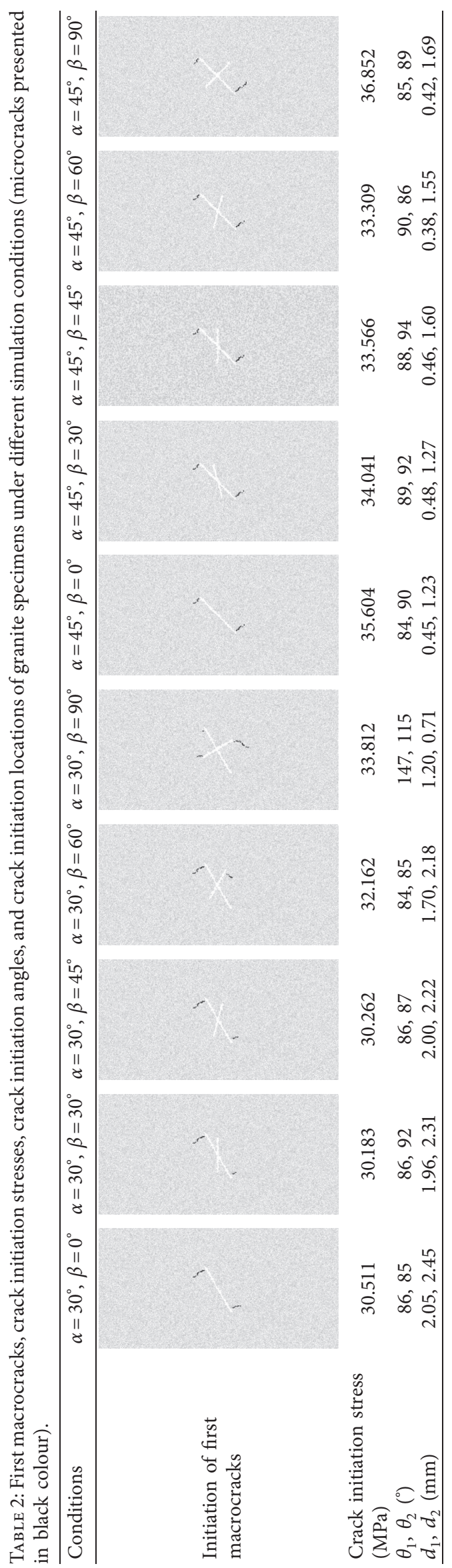




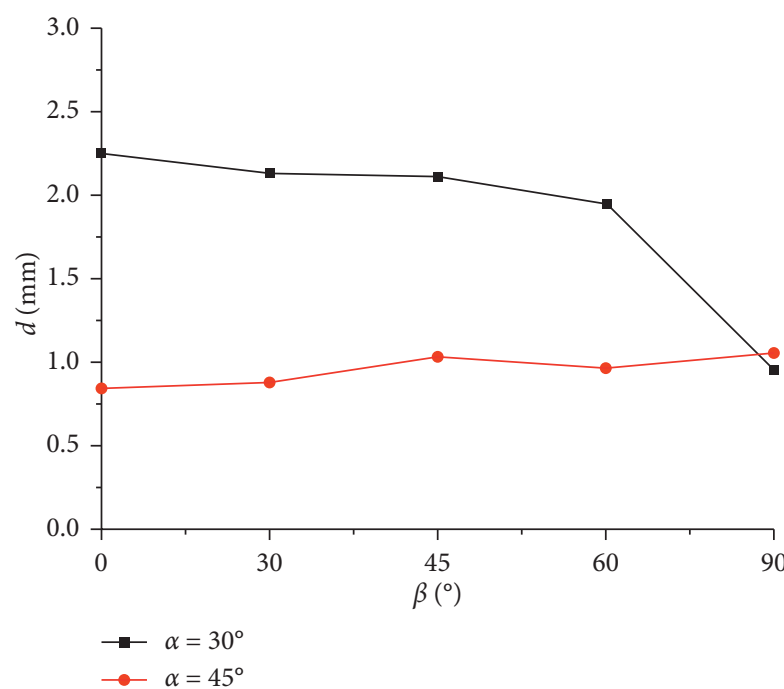

FiguRE 6: Variations of crack initiation locations with $\beta$.

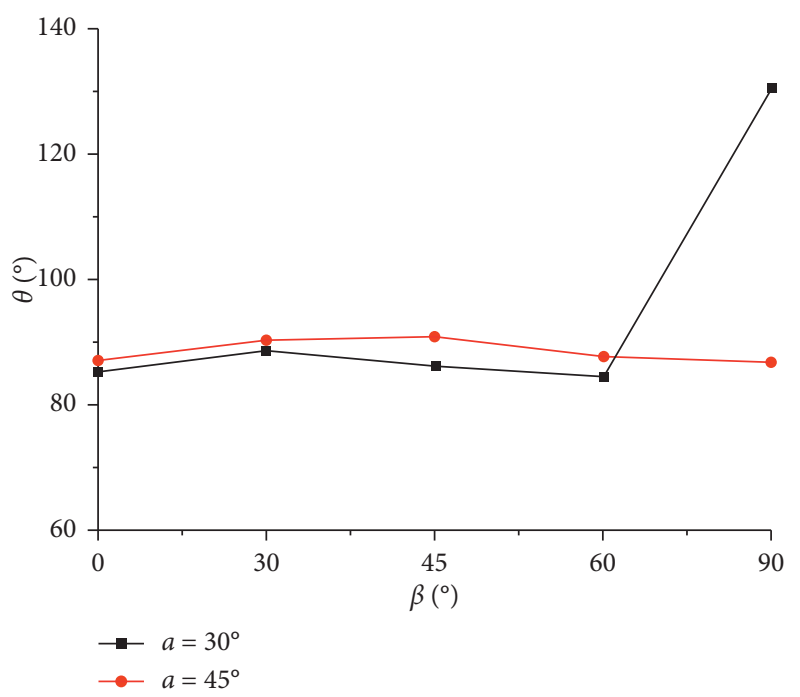

Figure 7: Variations of crack initiation angles with $\beta$.

the black segment. The thick black line with an arrowhead stands for the shrink direction of tensile force concentration zone around the main flaw. The thick red line with an arrowhead stands for the shrink direction of tensile force concentration zone around the secondary flaw. As $\beta$ varied from $0^{\circ}$ to $90^{\circ}$, the included angles of $\varphi$ between the secondary flaw direction and horizontal direction were $30^{\circ}, 0^{\circ}$, $-15^{\circ},-30^{\circ}$, and $-60^{\circ}$ along the clockwise direction, respectively. When $\alpha=30^{\circ}$ and $\beta=30^{\circ}$, i.e., $\alpha=30^{\circ}$ and $\varphi=0^{\circ}$, the tensile force concentration region around the main flaw shrank towards the flaw tips, and the tensile force concentration region around the secondary flaw were almost around it except at its tips. The tensile force concentrations close to main flaw tips were enhanced by being superposed with parts of tensile forces around the secondary flaw. Also, due to the shrink of tensile force concentration region around the main flaw, the compression force concentrations

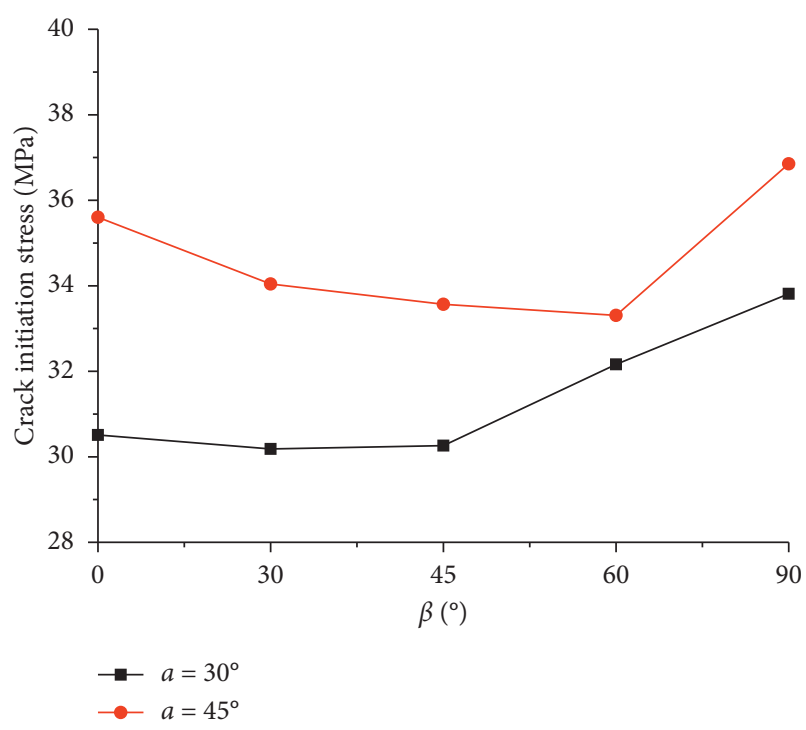

FIGURE 8: Variations of crack initiation stresses with $\beta$.

of the secondary flaw tips were weakened, which were crowded by a small number of black segment, as shown in the black boxes in Table 4 . The secondary flaw tips were still under compression. Thus, the first macrocracks easily initiated from the main flaw compared that at $\alpha$ of $30^{\circ}$ and $\beta$ of $0^{\circ}$. As $\beta$ varied from $30^{\circ}$ to $90^{\circ}$, i.e., $\varphi$ varies from $-15^{\circ}$ to $-60^{\circ}$, the tensile force concentration zone around the secondary flaw shrank from right tip towards the left tip along the top flaw surface and from left tip towards right tip along the bottom flaw surface. That means the tensile force concentration regions around the secondary flaw moved away the main flaw tips, and the tensile force concentrations close to main flaw tips were reduced with $\beta$. Therefore, the crack initiation stress at $\alpha$ of $30^{\circ}$ and $\beta$ of $45^{\circ}$ was larger than that at $\alpha$ of $30^{\circ}$ and $\beta$ of $30^{\circ}$ and small than at $\alpha$ of $30^{\circ}$ and $\beta$ of $0^{\circ}$. On the one hand, the tensile force concentration zone around the secondary flaws shrank towards its tips. On the other hand, the secondary flaws tips became more and more close to the tensile force concentration zone close to main flaw tips. Therefore, the tensile force concentrations close to secondary flaw tips were enhanced with $\beta$, which were crowded by less black segments and more red segments, especially at $\alpha$ of $30^{\circ}$ and $\beta$ of $90^{\circ}$. And this may cause the first macrocrack initiate from the secondary flaw, as shown in Table 2. Thus, the corresponding crack initiation stress was relatively large due to a large value of $\varphi$ and flaw length.

4.1.2. $\alpha=45^{\circ}$. Table 5 gives the parallel bonding forces around the crossing-double-flaws at $\alpha$ of $45^{\circ}$ when the first macrocracks initiate. In Table 5 , the red segment, thick black line with an arrowhead, and thick red line with an arrowhead are same as in Table 4 . As $\beta$ varied from $0^{\circ}$ to $90^{\circ}$, the included angles of $\varphi$ between the secondary flaw and horizontal direction were $15^{\circ}, 0^{\circ},-15^{\circ}$, and $-45^{\circ}$ along the clockwise direction, respectively. When $\alpha=45^{\circ}$ and $\beta=30^{\circ}$, i.e., $\alpha=45^{\circ}$ and $\varphi=0^{\circ}$, the tensile force concentration zone around secondary flaw shrank from left tip towards the right 


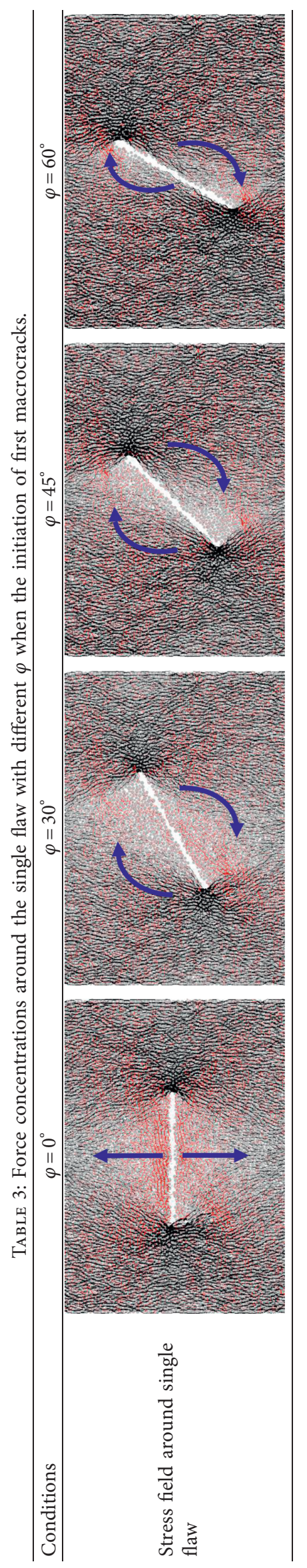


TABLE 4: Force concentrations around the crossing-double-flaws at $\alpha$ of $30^{\circ}$ when the initiation of first macrocracks.

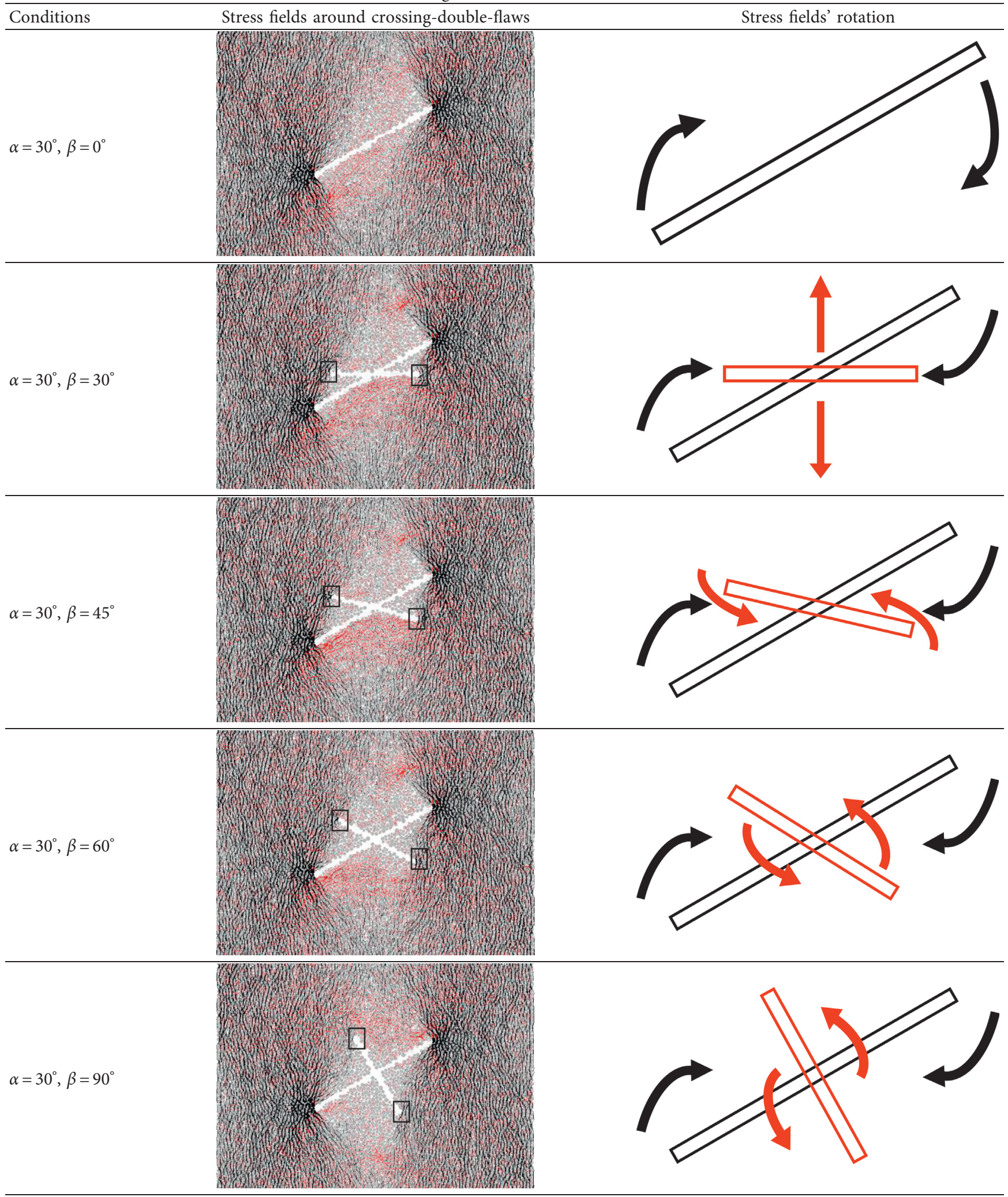

tip along the top flaw surface, and from right tip towards left tip along the bottom flaw surface. When $\alpha=45^{\circ}$ and $\beta=45^{\circ}$, i.e., $\alpha=45^{\circ}$ and $\varphi=0^{\circ}$, the tensile force concentration region around secondary flaw were almost around the secondary flaw except at its tips. When $\alpha=45^{\circ}$ and $\beta=60^{\circ}$ or $90^{\circ}$, i.e., $\alpha=45^{\circ}$ and $\varphi=-15^{\circ}$ or $-45^{\circ}$, the tensile force concentration zone around secondary flaw shrank from right tip towards the left tip along the top flaw surface and from left tip 
TABLE 5: Force concentrations around the crossing-double-flaws at $\alpha$ of $45^{\circ}$ when the initiation of first macrocracks.

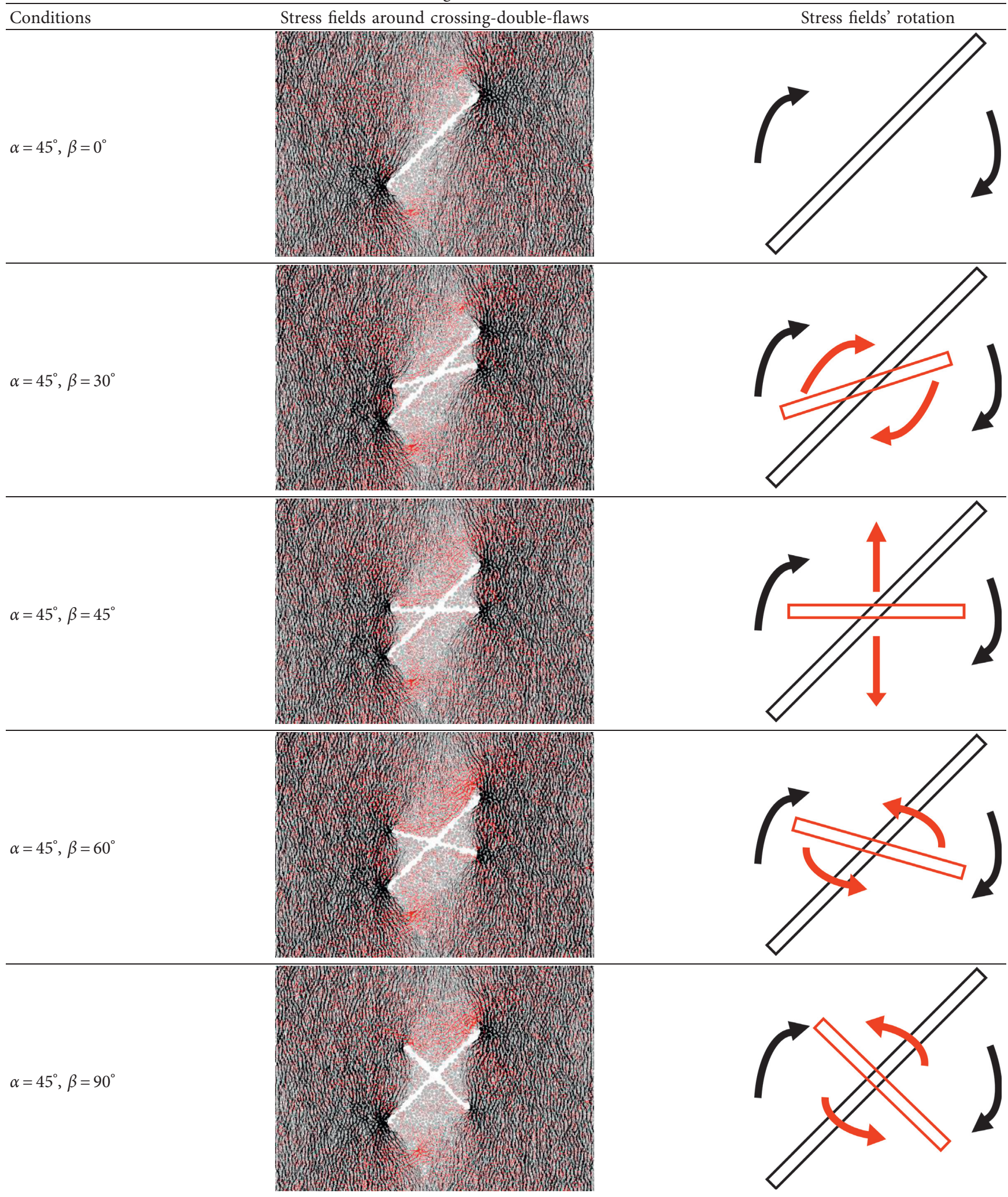

towards right tip along the bottom flaw surface. If the shrink direction of tensile force concentration regions around the secondary flaw at $\alpha$ of $45^{\circ}$ and $\beta$ of $30^{\circ}$ was taken as a reference direction, the tensile force concentration regions around the secondary flaw expanded along the anticlockwise direction at $\beta$ of $45^{\circ}$ and shrank along the anticlockwise direction at $\beta$ of $60^{\circ}$ and $90^{\circ}$. These meant the tensile force concentration regions around secondary flaw 


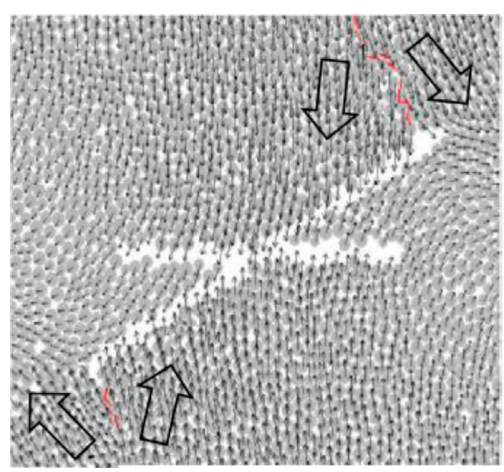

(a)

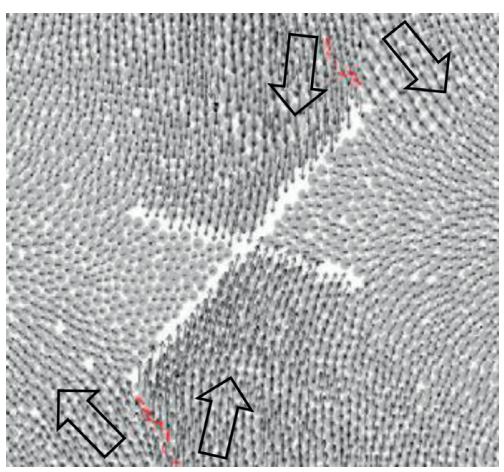

(d)

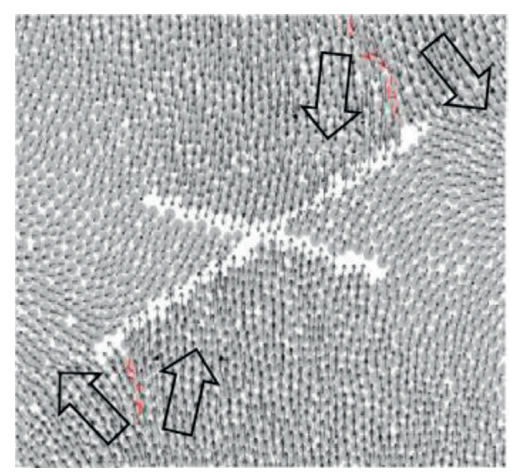

(b)

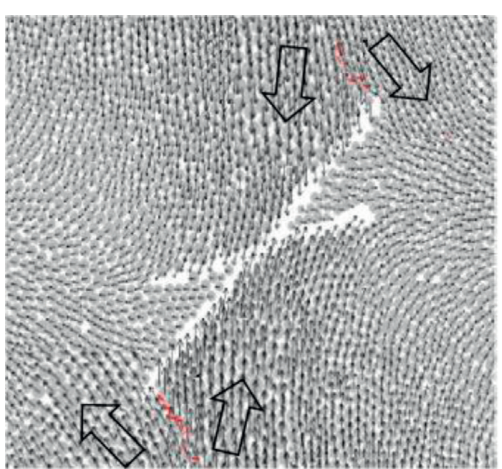

(c)

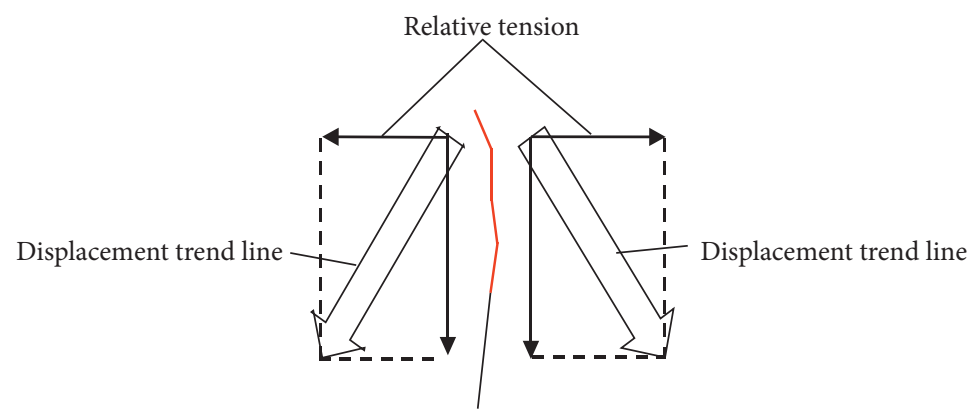

First macrocracks

(e)

Figure 9: Typical microdisplacement field distributions and of displacement-filed model of granite specimens. (a) $\alpha=30^{\circ}$ and $\beta=30^{\circ}$, (b) $\alpha=30^{\circ}$ and $\beta=45^{\circ}$, (c) $\alpha=45^{\circ}$ and $\beta=30^{\circ}$, (d) $\alpha=45^{\circ}$ and $\beta=60^{\circ}$, and (e) displacement-filed model.

moved close to main flaw tips at $\beta$ of $45^{\circ}$ and moved always the main flaw tips at $\beta$ of $60^{\circ}$ and $90^{\circ}$. The shrink degree increased with $\beta$ varying from $60^{\circ}$ to $90^{\circ}$. Therefore, the tensile force concentration close to the main flaw was enhanced firstly at $\beta$ of $45^{\circ}$ and then weakened at $\beta$ of $60^{\circ}$ and $90^{\circ}$. The corresponding crack initiation stress decreased firstly and then increased.

4.2. Microdisplacement Field Analysis. The microdisplacement filed (MDF) distribution is helpful to reveal the micromechanism of crack initiation behavior in granite specimen containing crossing-double-flaws under uniaxial compression.

Figures 9(a)-9(d) illustrate MDF distributions of granite specimen under different simulation conditions when first macrocracks initiated. Red segments presented the microcracks. Thin black lines with arrowheads stood for displacement vectors of the particles in the numerical model. Thick black lines with arrowheads stood for the displacement trend on both sides of first macrocrack, which were not filled with a colour.

According to displacement trends of particles on both sides of first macrocracks, a type of displacement filed was obtained when the first macrocracks initiate, as shown in Figure 9(e). Firstly, the particles moved in the same direction, then they moved apart in two directions. Thus, a relative tension was formed, and microcracks were generated. Finally, a macrocrack was generated when three or more microcracks connected in this study. The type of displacement filed was basically consistent with research results studied by Zhang and Wong [33], Huang et al. [22], and Yin et al. [38].

\section{Conclusions}

In this study, the uniaxial compression tests on granite specimens with crossing-double-flaws of different lengths were simulated by PFC. The crack initiation behaviors of granite specimens were studied. The following conclusions were achieved:

(1) Crack initiation models were all tensile wing cracks. First, macrocracks did not exactly initiate from the main flaw with a length of $30 \mathrm{~mm}$, and they can initiate from the secondary flaw with a length of $20 \mathrm{~mm}$ at $\alpha$ of $30^{\circ}$ and $\beta$ of $90^{\circ}$ and from the main and secondary flaws at $\alpha$ of $30^{\circ}$ and $\beta$ of $60^{\circ}$. These are mainly caused by the superposition of stress fields around the main and secondary flaws as $\beta$ varies from $0^{\circ}$ to $90^{\circ}$, especially the tensile force concentration zones' superposition. The tensile forces' concentration region around the flaw shrank towards flaw tips with the increase of the flaw's inclinations measured horizontally. Under superposition effects of stress fields, the crack initiation stress decreased firstly and then increased with $\beta$ at $\alpha$ of $30^{\circ}$ and $45^{\circ}$. 
(2) Crack initiation locations were close to flaw tips but not restricted to them. The crack initiation angle was determined by the flaw where first macrocracks initiated from. Generally, the larger the flaw inclinations measured horizontally was, the smaller the distances between crack initiation locations and flaw tips were, and the greater the crack initiation angle was.

(3) A type of displacement filed was found when first macrocracks initiated. Firstly, the particles moved in the same direction, and then they moved apart in two directions. Thus, a relative tension was formed, and microcracks were generated. A macrocrack was generated when three or more microcracks connected in this study.

\section{Data Availability}

The data used to support the findings of this study are included within the article.

\section{Conflicts of Interest}

The authors declare that they have no conflicts of interest.

\section{Acknowledgments}

This study was supported by National Natural Science Foundation of China (51904167, 51474134, and 51774194), Taishan Scholars Project, Taishan Scholar Talent Team Support Plan for Advantaged \& Unique Discipline Areas, Shandong Provincial Natural Science Fund for Distinguished Young Scholars (JQ201612), Shandong Provincial Key Research and Development Plane (2017GSF17112), Project of Open Research Fund for Key Laboratories of Ministry of Education for safe and efficient mining of coal mine (JYBSYS2019201), and Scientific Research Foundation of Shandong University of Science and Technology for Recruited Talents (2019RCJJ019).

\section{References}

[1] Z. H. Zhao, W. Sun, M. Z. Zhang, X. J. Gao, and S. J. Chen, "Fracture mechanical behavior of cracked cantilever roof with large cutting height mining," Shock and Vibration, vol. 2020, Article ID 1641382, 10 pages, 2020.

[2] Z. Qin, H. L. Fu, and X. X. Chen, "A study on altered granite meso-damage mechanisms due to water invasion-water loss cycles," Environmental Earth Sciences, vol. 78, no. 14, p. 428, 2019.

[3] J. Wang, S.-C. Li, L.-P. Li, P. Lin, Z.-H. Xu, and C.-L. Gao, "Attribute recognition model for risk assessment of water inrush," Bulletin of Engineering Geology and the Environment, vol. 78, no. 2, pp. 1057-1071, 2019.

[4] N. Zhang, W. Liu, Y. Zhang, P. F. Shan, and X. L. Shi, "Microscopic pore structure of surrounding rock for underground strategic petroleum reserve (SPR) caverns in bedded rock salt," Energies, vol. 13, no. 7, p. 1565, 2020.

[5] F. Q. Ren, C. Zhu, and M. C. He, "Moment tensor analysis of acoustic emissions for cracking mechanisms during schist strain burst," Rock Mechanics and Rock Engineering, vol. 53, no. 1, pp. 153-170, 2020.

[6] D. K. Liu, Z. L. Gu, R. X. Liang et al., "Impacts of pore-throat system on fractal characterization of tight sandstones," Geofluids, vol. 2020, Article ID 4941501, 17 pages, 2020.

[7] D. Z. Ren, D. S. Zhou, D. K. Liu, F. J. Dong, S. W. Ma, and H. Huang, "Formation mechanism of the upper triassic yanchang formation tight sandstone reservoir in ordos basin-take chang 6 reservoir in jiyuan oil field as an example," Journal of Petroleum Science and Engineering, vol. 178, pp. 497-505, 2019.

[8] G. Feng, X. C. Wang, M. Wang, and Y. Kang, "Experimental investigation of thermal cycling effect on fracture characteristics of granite in a geothermal-energy reservoir," Engineering Fracture Mechanics, vol. 235, Article ID 107180, 2020.

[9] B. R. Lawn and A. G. Evans, "A model for crack initiation in elastic/plastic indentation filed," Journal of Materials Science, vol. 12, no. 11, pp. 2195-2199, 1997.

[10] A. Basu and D. A. Mishra, "A method for estimating crackinitiation stress of rock materials by porosity," Journal of the Geological Society of India, vol. 84, no. 4, pp. 397-405, 2014.

[11] B. Shen, O. Stephansson, H. H. Einstein, and B. Ghahremanl, "Coalescence of fractures under shear stresses in experiments," Journal of Geophysical Research, vol. 100, no. B4, pp. 5975-5990, 1995.

[12] A. Bobet, "The initiation of secondary cracks in compression," Engineering Fracture Mechanics, vol. 66, no. 2, pp. 187-219, 2000.

[13] L. N. Y. Wong and H. H. Einstein, "Systematic evaluation of cracking behavior in specimens containing single flaws under uniaxial compression," International Journal of Rock Mechanics and Mining Sciences, vol. 46, no. 2, pp. 239-249, 2009.

[14] P. Lin, R. H. C. Wong, R.-K. Wang, and W. Y. Zhou, "Crack growth mechanism failure behavior of specimen containing single flaw with different angles," Chinese Journal of Rock Mechanics and Engineering, vol. 24, no. 2, pp. 5652-5657, 2005.

[15] R. H. C. Wong and K. T. Chau, "Crack coalescence in a rocklike material containing two cracks," International Journal of Rock Mechanics and Mining Sciences, vol. 35, no. 2, pp. 147-164, 1998.

[16] R.H. Cao, P. Cao, H. Lin, C.-Z. Pu, and K. Ou, "Mechanical behavior of brittle rock-like specimens with pre-existing fissures under uniaxial loading, experimental studies and particle mechanics approach," Rock Mechanics and Rock Engineering, vol. 49, no. 3, pp. 763-783, 2016.

[17] X. P. Zhou, J. Bi, and Q. H. Qian, "Numerical simulation of crack growth and coalescence in rock materials containing multiple pre-existing flaws," Rock Mechanics and Rock Engineering, vol. 48, no. 3, pp. 1097-1114, 2015.

[18] G. M. Latha and A. Garaga, "Elasto-plastic analysis of jointed rocks using discrete continuum and equivalent continuum approaches," International Journal of Rock Mechanics and Mining Sciences, vol. 53, pp. 56-63, 2012.

[19] Z. H. Zhao, M. Z. Zhang, Q. Ma, and B. S. Chen, "Deviation effect of coaxiality on the rock brazilian split," Advances in Mathematical Physics, vol. 2020, Article ID 5782457, 8 pages, 2020.

[20] H. Lee and S. Jeon, "An experimental and numerical study of fracture coalescence in pre-cracked specimens under uniaxial compression," International Journal of Solids and Structures, vol. 48, no. 6, pp. 979-999, 2011.

[21] S.-Q. Yang, X.-R. Liu, and H.-W. Jing, "Experimental investigation on fracture coalescence behavior of red sandstone 
containing two unparallel fissures," International Journal of Rock Mechanics and Mining Sciences, vol. 63, pp. 82-92, 2013.

[22] Y.-H. Huang, S.-Q. Yang, W.-L. Tian, W. Zeng, and L.-Y. Yu, "An experimental study on fracture mechanical behavior of rock-like materials containing two unparallel fissures under uniaxial compression," Acta Mechanica Sinica, vol. 32, no. 3, pp. 442-455, 2016.

[23] S. R. Zhang, F. Sun, C. Wang, and L. Yan, "Discrete element analysis of crack propagation in rocks under biaxial compression," Chinese Journal of Rock Mechanics and Engineering, vol. 32, no. 2, pp. 3083-3091, 2013.

[24] R. H. C. Wong, K. T. Chau, C. A. Tang, and P. Lin, "Analysis of crack coalescence in rock-like materials containing three flaws-part I: experimental approach," International Journal of Rock Mechanics and Mining Sciences, vol. 38, no. 7, pp. 909-924, 2001.

[25] C. A. Tang, P. Lin, R. H. C. Wong, and K. T. Chau, "Analysis of crack coalescence in rock-like materials containing three flaws-part II: numerical approach," International Journal of Rock Mechanics and Mining Sciences, vol. 38, no. 7, pp. 925-939, 2001.

[26] M. Sagong and A. Bobet, "Coalescence of multiple flaws in a rock-model material in uniaxial compression," International Journal of Rock Mechanics and Mining Sciences, vol. 39, no. 2, pp. 229-241, 2002.

[27] X. Z. Sun, B. Shen, and B. L. Zhang, "Experimental study on propagation behavior of three-dimensional cracks influenced by intermediate principal stress," Geomechanics and Engineering, vol. 14, no. 2, pp. 195-202, 2018.

[28] L. Li, R. H. C. Wong, Z. Han, L. I. Haiyun, and Y. Liu, "Experimental and theoretical analyses of three-dimensional surface crack propagation," Chinese Journal of Rock Mechanics and Engineering, vol. 31, no. 2, pp. 311-318, 2012.

[29] A. V. Dyskin, L. N. Germanovich, and K. B. Ustinov, "A 3-D model of wing crack growth and interaction," Engineering Fracture Mechanics, vol. 63, no. 1, pp. 81-110, 1999.

[30] S. J. Chen, D. W. Yin, N. Jiang, F. Wang, and Z. F. Zhao, "Mechanical properties of oil shale-coal composite samples," International Journal of Rock Mechanics and Mining Sciences, vol. 123, Article ID 104120, 2019.

[31] S. J. Chen, D. W. Yin, N. Jiang, F. Wang, and W. J. Guo, "Simulation study on effects of loading rate on uniaxial compression failure of composite rock-coal layer," Geomechanics and Engineering, vol. 17, no. 4, pp. 333-342, 2019.

[32] D. W. Yin, S. J. Chen, X. Q. Liu, and H. F. Ma, "Effect of joint angle in coal on failure mechanical behavior of rock-coal combined body," Quarterly Journal of Engineering Geology and Hydrogeology, vol. 51, no. 2, pp. 202-209, 2018.

[33] X.-P. Zhang and L. N. Y. Wong, "Cracking processes in rocklike material containing a single flaw under uniaxial compression: a numerical study based on parallel bonded-particle model approach," Rock Mechanics Rock Engineering, vol. 45, no. 5, pp. 711-737, 2011.

[34] O. Reyes and H. H. Einstein, "Failure mechanism of fractured rock-a fracture coalescence model," in Proceedings of the Seventh International Congress on Rock Mechanics, pp. 333340, Aachen, Germany, 1991.

[35] B. Shen and O. Stephansson, "Modification of the G-criterion for crack propagation subjected to compression," Engineering Fracture Mechanics, vol. 47, no. 2, pp. 177-189, 1994.

[36] P. H. S. W. Kulatilake, B. Malama, and J. Wang, "Physical and particle flow modeling of jointed rock block behavior under uniaxial loading," International Journal of Rock Mechanics and Mining Sciences, vol. 38, no. 5, pp. 641-657, 2001.
[37] Y. H. Huang and S. Q. Yang, "Discrete element study on strength and failure behavior of jointed sandstone with two sets of cross-joints," Journal of China Coal Society, vol. 40, no. 1, pp. 76-84, 2015.

[38] D. W. Yin, S. J. Chen, X. Q. Liu, and H. F. Ma, "Simulation study on strength and failure characteristics for granite with a set of cross-joints of different lengths," Advances in Civil Engineering, vol. 2018, Article ID 2384579, 10 pages, 2018.

[39] X. P. Zhang, G. Wang, Y. J. Jiang, and N. Huang, "Simulation research on granite compression test based on particle discrete element model," Rock and Soil Mechanics, vol. 35, no. 1, pp. 99-105, 2014.

[40] L. N. Y. Wong, Crack Coalescence in Molded Gypsum and Carrara Marble, Massachusetts Institute of Technology, Cambridge, MA, USA, 2008.

[41] E. Z. Lajtai, "A theoretical and experimental evaluation of the Griffith theory of brittle fracture," Tectonophysics, vol. 11, no. 2, pp. 129-156, 1971. 